\title{
Effect of oxygen concentration on the growth of Nannochloropsis sp. at low light intensity
}

\author{
Sayam Raso • Bernard van Genugten • \\ Marian Vermuë • René H. Wijffels
}

Received: 26 November 2010 / Revised and accepted: 22 July 2011 /Published online: 29 September 2011

(C) The Author(s) 2011. This article is published with open access at Springerlink.com

\begin{abstract}
In large-scale microalgal production in tubular photobioreactors, the build-up of $\mathrm{O}_{2}$ along the tubes is one of the major bottlenecks to obtain high productivities. Oxygen inhibits the growth, since it competes with carbon dioxide for the Rubisco enzyme involved in the $\mathrm{CO}_{2}$ fixation to generate biomass. The effect of oxygen on growth of Nannochloropsis sp. was experimentally determined in a fully controlled flat-panel photobioreactor operated in turbidostat mode using an incident photon flux density of $100 \mu \mathrm{mol}$ photons $\mathrm{m}^{-2} \mathrm{~s}^{-1}$ and with only the oxygen concentration as variable parameter. The dissolved oxygen concentration was varied from 20 to $250 \%$ air saturation. Results showed that there was no clear effect of oxygen concentration on specific growth rate (mean of $0.48 \pm$ 0.40 day $^{-1}$ ) upon increasing the oxygen concentration from $20 \%$ to $75 \%$ air saturation. Upon further increasing the oxygen concentration, however, a linear decrease in specific growth rate was observed, ranging from $0.48 \pm 0.40$ day $^{-1}$ at a dissolved oxygen concentration of $75 \%$ air saturation to $0.18 \pm 0.01$ day $^{-1}$ at $250 \%$ air saturation. In vitro data on isolated Rubisco were used to predict the quantum yield at different oxygen concentrations in the medium. The predicted decrease in quantum yield matches well with the observed decrease that was measured in vivo. These results indicate that the effect of oxygen on growth of Nannochloropsis sp. at low light intensity is only due to competitive inhibition of the Rubisco enzyme. At these sub-saturating light conditions, the presence of high concentrations of oxygen in the medium induced slightly higher carotenoid
\end{abstract}

\footnotetext{
S. Raso • B. van Genugten $\cdot$ M. Vermuë $(\bowtie) \cdot R$. H. Wijffels Bioprocess Engineering, Department of Agrotechnology and Food Sciences, Wageningen University,

P. O. Box 8129, 6700 EV Wageningen, The Netherlands

e-mail: marian.vermue@wur.nl

URL: www.algae.wur.nl
}

content, but the increased levels of this protective antioxidant did not diminish the growth-inhibiting effects of oxygen on the Rubisco.

Keywords $\mathrm{O}_{2}$ concentration - Tubular photobioreactor . Photorespiration $\cdot$ Nannochloropsis sp.

\section{Introduction}

For large-scale cultivation of Nannochloropsis sp., tubular photobioreactor systems have been developed (Cheng-Wu et al. 2001; Richmond and Cheng-Wu 2001; Chini Zittelli et al. 1999, 2003; Zou and Richmond 1999). In these photobioreactors, however, accumulation of oxygen is one of the major problems, since it inhibits the growth of microalgae (Molina Grima et al. 2001; Livansky 1996; Ogawa et al. 1980; Pulz 2001; Vonshak et al. 1996; Weissman and Goebel 1988). There are two mechanisms largely responsible for the deleterious effects on growth of the microalgae: the competitive effect of $\mathrm{O}_{2}$ on Rubisco (photorespiration) and photo-inhibition which causes cell damage of photosystem II by the generation of reactive oxygen species (ROS; Ohnishi et al. 2005). Photorespiration only takes place during the dark reaction of photosynthesis and is thus independent of the light conditions used, while the ROS are formed if the algae receive excessive amounts of light in the light reaction of the photosynthesis. In this study, we will focus only on the photorespiration reaction as we work at a low irradiance of $100 \mu \mathrm{mol}$ photons $\mathrm{m}^{-2} \mathrm{~s}^{-1}$, where photo-inhibition effects in Nannochloropsis sp. are negligible (Ogawa et al. 1980; Sukenik 1991; Sukenik et al. 1997).

The inhibiting effects of oxygen on the in vivo productivity are often referred to in literature (Kitaya et al. 
2005; Livansky 1996; McMinn et al. 2005; Ogawa et al. 1980; Ugwu et al. 2007; Kliphuis et al. 2011). In hardly any of the reported studies, however, the effect of $\mathrm{O}_{2}$ was measured as independent parameter at controlled conditions of light intensity, $\mathrm{pH}$, temperature, and biomass concentration. The effects on growth therefore often reflect a combined effect of light and oxygen on photosynthesis. In addition, up till now quantification of the direct effect of oxygen on in vivo growth and productivity of Nannochloropsis sp. has never been performed. In our study, the effects of oxygen levels on the growth of Nannochloropsis sp. have been determined in a flat-panel photobioreactor operating in turbidostat mode to ensure controlled conditions of sub-saturating light, $\mathrm{pH}$, temperature, and mixing. These in vivo growth rates of Nannochloropsis sp. at the different oxygen concentrations are compared with the growth rates, predicted using the in vitro kinetic parameters as determined by Tchernov et al. (2008) for isolated Rubisco from this species.

\section{Materials and methods}

Nannochloropsis sp. (CCAP 211/78) was pre-cultured in an incubator $(100 \mathrm{rpm})$, provided with a light-dark cycle of 18:6 $\mathrm{h}$ and a light intensity of $41 \mu \mathrm{mol}$ photons $\mathrm{m}^{-2} \mathrm{~s}^{-1}$ at $\mathrm{pH} 7.8$ and with $2 \%$ of $\mathrm{CO}_{2}$-enriched air for 1 week before inoculation of the flat-panel photobioreactor. Modified Zou medium was used to pre-culture and grow Nannochloropsis sp. (Table 1). Stock solutions of the trace elements, FeEDTA, as well as the phosphate buffer solution were

Table 1 Composition of the modified Zou medium used for growth of Nannochloropsis sp.

\begin{tabular}{|c|c|}
\hline Compounds & Concentration $(\mathrm{mM})$ \\
\hline $\mathrm{NaCl}$ & 419.38 \\
\hline $\mathrm{MgSO}_{4}$ & 54.81 \\
\hline $\mathrm{MgCl}_{2} \cdot 6 \mathrm{H}_{2} \mathrm{O}$ & 27.55 \\
\hline $\mathrm{CaCl}_{2} \cdot 2 \mathrm{H}_{2} \mathrm{O}$ & 10.20 \\
\hline $\mathrm{CO}\left(\mathrm{NH}_{2}\right)$ & 19.98 \\
\hline $\mathrm{NaHCO}_{3}$ & 0.476 \\
\hline EDTA-FE(III)-Na-salt & 3.70 \\
\hline $\mathrm{K}_{2} \mathrm{HPO}_{4}$ & 57.41 \\
\hline $\mathrm{KH}_{2} \mathrm{PO}_{4}$ & 14.70 \\
\hline \multicolumn{2}{|l|}{ Trace elements } \\
\hline $\mathrm{Na}_{2}$ EDTA & 0.26 \\
\hline $\mathrm{CuSO}_{4} \cdot 5 \mathrm{H}_{2} \mathrm{O}$ & 0.03 \\
\hline $\mathrm{ZnSO}_{4} \cdot 7 \mathrm{H}_{2} \mathrm{O}$ & 0.04 \\
\hline $\mathrm{CoCl}_{2} \cdot 2 \mathrm{H}_{2} \mathrm{O}$ & 0.03 \\
\hline $\mathrm{MnCl}_{2} \cdot 4 \mathrm{H}_{2} \mathrm{O}$ & 0.46 \\
\hline $\mathrm{Na}_{2} \mathrm{MoO}_{4} \cdot 2 \mathrm{H}_{2} \mathrm{O}$ & 0.13 \\
\hline
\end{tabular}

autoclaved separately and kept at $4^{\circ} \mathrm{C}$. The medium was filter-sterilized using a $0.2-\mu \mathrm{m}$ filter, and after adding the other stock solutions (phosphate, iron-EDTA), the $\mathrm{pH}$ was adjusted using $\mathrm{NaOH}$ or $\mathrm{HCl}$.

Cultivation of the algae in the flat-panel photobioreactor

To measure the effect of oxygen at controlled light and culture conditions, a flat-panel photobioreactor with culture volume of $1.5 \mathrm{~L}$ and a light path of $2.8 \mathrm{~cm}$ was used. Constant and homogeneous illumination at wavelength $637 \mathrm{~nm}$ was provided by a red-light emitting diode (PSIPhoton Systems Instruments, Czech Republic). After inoculation, the algae were allowed to grow batchwise for 9 days at controlled $\mathrm{pH}(\mathrm{pH} 7.8)$ and temperature $\left(25^{\circ} \mathrm{C}\right)$ and a total gas flow rate of $0.5 \mathrm{LL}^{-1} \mathrm{~min}^{-1}$ using an average irradiance of $100 \mu \mathrm{mol}$ photons $\mathrm{m}^{-2} \mathrm{~s}^{-1}$. The irradiance at the back of the flat-panel photobioreactor was set at $12 \mu \mathrm{mol}$ photons $\mathrm{m}^{-2} \mathrm{~s}^{-1}$ using a light sensor (LICOR-190) that was connected to a control unit. This unit controlled the medium in- and outflow pumps to set the turbidity. When the light intensity at the back reached $12 \mu \mathrm{mol}$ photons $\mathrm{m}^{-2} \mathrm{~s}^{-1}$, the photobioreactor was switched into turbidostat mode and was operated for 6 days at a dissolved oxygen (DO) concentration corresponding to $100 \%$ air saturation to allow the cells to adjust to turbidostat operation conditions and continuous illumination. A photosynthesis versus irradiance (PE) curve was measured for cells adapted to these light conditions and an oxygen concentration of $100 \%$ air saturation. Net photosynthesis rate was measured as oxygen evolution in a Liquid-Phase Oxygen Electrode Chamber (Hansatech, DW3) equipped with an oxygen control electrode unit (Hansatech, Oxy-lab) at $25^{\circ} \mathrm{C}$. Light is supplied via a red LED light source (Hansatech LH36/2R) with wave length of $637 \mathrm{~nm}$. The PE curve (Fig. 1) confirmed that the algae

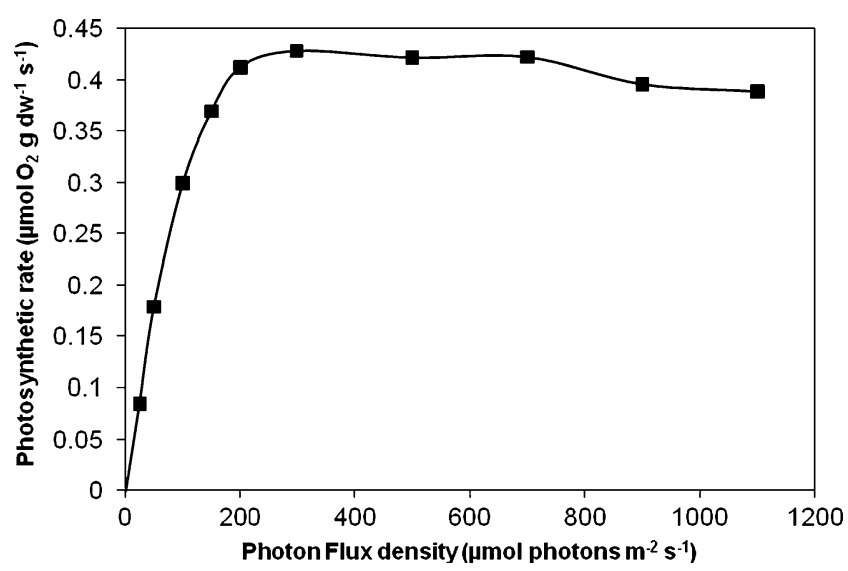

Fig. 1 PE curve of Nannochloropsis sp. grown at 100\% air saturation and adapted to an irradiance of $100 \mu \mathrm{mol}$ photons $\mathrm{m}^{-2} \mathrm{~s}^{-1}$ 
indeed experience sub-saturating light conditions at photon flux densities $<200 \mu \mathrm{mol}$ photons $\mathrm{m}^{-2} \mathrm{~s}^{-1}$.

During all runs, possible foam formation was controlled by an automatic foam control unit. Before entering the flatpanel photobioreactor, the incoming gas flow was humidified and the outgoing gas flow was led through a condenser to prevent loss of the medium by evaporation. The medium bottle was connected with a bag containing $\mathrm{CO}_{2}$ to compensate for possible $\mathrm{pH}$ fluctuations during the turbidostat run. In the medium, $20 \mathrm{mM}$ urea was used as nitrogen source to ensure no $\mathrm{pH}$ fluctuations occur due to utilization of the $\mathrm{N}$-source.

The oxygen concentration during the turbidostat operation was monitored by a DO sensor (Applisens DO sensor) and controlled by adjusting the concentration of oxygen in the incoming gas flow, while the total gas flow $\left(\mathrm{O}_{2}\right.$ mixed with pure $\mathrm{N}_{2}$ and pure $\mathrm{CO}_{2}$ ) was kept constant at $0.5 \mathrm{~L}$ $\mathrm{L}^{-1} \mathrm{~min}^{-1}$. It was subsequently set for 4 days at 75,50 , and $25 \%$ air saturation and at no additional $\mathrm{O}_{2}$. A 2-day time interval was used to allow for adaptation of the algae to the new $\mathrm{O}_{2}$ concentration before samples were taken. A second and third run were performed to test the effects of 125,150 , 175,200 , and $250 \%$ air saturation. After the run at $250 \%$, the oxygen concentration was increased to $300 \%$. After 1 day at $300 \%$ air saturation, however, the cells became pale, indicating that they lost chlorophyll, and a sudden increase in the $\mathrm{OD}_{680} / \mathrm{OD}_{530}$ ratio indicated that contamination of the culture by bacteria occurred.

\section{Biomass concentration and dry weight}

Samples of approximately $100 \mathrm{~mL}$ were taken aseptically each day during the subsequent turbidostat runs for off-line measurement of the biomass concentration and determination of the dry weight. The algal biomass concentration was monitored by the optical density at $530 \mathrm{~nm}\left(\mathrm{OD}_{530}\right)$ and $680 \mathrm{~nm}\left(\mathrm{OD}_{680}\right)$. The ratio $\mathrm{OD}_{680} / \mathrm{OD}_{530}$ was used as an indicator for the amount of chlorophyll per amount of biomass and as an indicator for possible contamination. In addition, the biomass dry weight concentration was determined by filtering samples (in triplicate) of the algal culture using pre-weight glass microfiber filters (Whatman). The algae were washed three times with ammonium formate $(0.5 \mathrm{M})$ to remove the precipitated salts and other non-organic substances and dried at $105^{\circ} \mathrm{C}$ for $24 \mathrm{~h}$, cooled overnight over silica gel in a desiccator, and weighed. In addition, the cell numbers and the distribution in the cell size were determined in a Coulter counter (Beckman Multisizer $3^{\mathrm{TM}}$, USA).

\section{Elemental composition and pigment content}

To assess possible effects of oxygen on the algal biomass composition, the elemental composition is determined for the algal cells growing at 100 and at $300 \%$ air saturation. Liquid samples were centrifuged for $10 \mathrm{~min}$ at a $1,750 \mathrm{rfc}$. The pellets were washed three times with de-mineralized water and re-suspended and centrifuged again. The remaining algae pellets were stored at $-20^{\circ} \mathrm{C}$. The frozen pellets were weighted and freeze-dried and ground to fine powder before further analysis of the biomass composition and moisture content. The $\mathrm{C}, \mathrm{H}$, and $\mathrm{N}$ contents of the freezedried samples of the algae growing at 100 and $300 \%$ oxygen were measured at $925^{\circ} \mathrm{C}$ in the oven of an elemental analyzer (EA 1110, ThermoQuest CE Instruments). Ash content was determined by burning the freezedried algae samples in an oven at $550^{\circ} \mathrm{C}$, to oxidize all organic material, leaving the ash residue. From these determinations, the oxygen $(\mathrm{O})$ content and subsequently the elemental composition of the algae could be calculated (C, H, O, N, and ash; Duboc et al. 1999).

Possible changes in pigment content due to increased oxygen concentrations were monitored by measuring the absorbance PAR spectrum (400-700 nm; Avants fibre optic spectrometer, The Netherlands). Based on the spectra, the ratio in carotenoid and chlorophyll content in the samples is determined from the absorption at $490 \mathrm{~nm}$ and $680 \mathrm{~nm}$.

\section{Specific growth rate and quantum yield}

During the turbidostat operation, the specific growth rate of the algae $(\mu)$ was determined from the dilution rate. For this the medium output per liquid volume of reactor was weighted and recorded every minute.

The specific growth rate was used to calculate the biomass yield $\left(Y_{\mathrm{x}, \mathrm{ph}}\right)$ on light energy, which is defined as the amount of biomass (grams dry weight) produced per mole photon absorbed in the PAR range:

$Y_{\mathrm{x}, \mathrm{ph}}=\mu \times V \times C_{\mathrm{x}} / A \times \Delta \mathrm{PFD}$

where $\mu$ is the specific growth rate $\left(\right.$ day $\left.^{-1}\right), V$ is culture volume of photobioreactor $\left(\mathrm{m}^{3}\right), C_{\mathrm{x}}$ is the biomass concentration $\left(\mathrm{g} \mathrm{dw} \mathrm{m}^{-3}\right), A$ is the illuminated area $\left(\mathrm{m}^{2}\right)$, and $\triangle \mathrm{PFD}$ (moles photons $\mathrm{m}^{-2}$ day $^{-1}$ ) is the difference in incident photon flux density (PFD) and the PFD measured at the back of the flat panel.

The quantum yield $\left(\mathrm{QY} ; \mathrm{mol} \mathrm{CO}_{2}\right.$ fixed/mole photon absorbed) is defined as

$\mathrm{QY}=\left(Y_{\mathrm{x}, \mathrm{ph}} / M_{\mathrm{wx}}\right) \times Y_{\mathrm{CO} 2, \mathrm{x}}$

where $M_{\mathrm{wx}}$ is the molar mass of the biomass ( $\mathrm{g} \mathrm{dw} / \mathrm{C}$-mole biomass) and $Y_{\mathrm{CO} 2, \mathrm{x}}$ is the amount of carbon dioxide needed to form one $\mathrm{C}$-mole of biomass $\left(\right.$ mole $\mathrm{CO}_{2} / \mathrm{C}$-mole biomass). 


\section{Results}

Growth at controlled oxygen conditions

A typical growth curve of Nannochloropsis sp. during a run in the 1.5-L flat-panel photobioreactor at different DO concentration is presented in Fig. 2. It shows that the algal cells were allowed to grow batchwise until an optical density $\mathrm{OD}_{530}$ of 1.5 was reached. After that, the turbidostat operation started and the cells were allowed to adjust for 3 days to the set oxygen concentration of $100 \%$ air saturation and off-line samples were taken during three subsequent days. This procedure was repeated for each tested oxygen concentration. The $\mathrm{OD}_{680} /$ $\mathrm{OD}_{530}$ ratio remained constant at the tested oxygen concentrations, which indicates that the algal cells were healthy and no contamination by other microorganisms took place.

Figure 3 shows the specific growth rate of the algae growing at sub-saturating light conditions with varying oxygen concentration from $20 \%$ to $250 \%$ air saturation. Upon increasing oxygen concentration from 20 to $75 \%$ air saturation, no clear effect of oxygen on specific growth rate is observed and the growth rate showed a mean average value of $0.48 \pm 0.40$ day $^{-1}$. Upon further increase of the oxygen concentration, the specific growth rate of Nannochloropsis sp. linearly decreases $\left(R^{2}=0.95\right)$ from $0.49 \pm 0.10$ day $^{-1}$ at DO of $75 \%$ air saturation to $0.18 \pm$ 0.01 day $^{-1}$ at DO of $250 \%$ air saturation. This decrease in specific growth rate can be solely attributed to the effects of oxygen, since all other conditions in the culture were kept constant.
Effects of oxygen concentration on cell concentration and cell composition

Off-line measurements of the cell concentration (cells $\left.\mathrm{mL}^{-1}\right)$ and the cell dry weight $\left(\mathrm{g} \mathrm{L}^{-1}\right)$ showed a small increase (Table 3), while total absorption area remained virtually constant at $0.10 \mathrm{~m}^{2} \mathrm{~L}^{-1}$ in all experiments. This indicates that the biomass content per cell might have changed, but no change in light absorption characteristics occurred as an effect of changing oxygen concentrations.

The ratio in carotenoid and chlorophyll content of the algae at different oxygen concentration again shows little effect of increased oxygen levels (Fig. 4). The ratio remained constant up to an oxygen concentration of $200 \%$ air saturation and only a slightly higher ratio was observed at $250 \%$ air saturation. Also the elemental composition of the algae remained virtually the same (Table 2); at $100 \%$ $\mathrm{O}_{2}$, the elemental composition was $\mathrm{CH}_{1.77} \mathrm{O}_{0.24} \mathrm{~N}_{0.15}$ and at $300 \% \mathrm{O}_{2}$, it was $\mathrm{CH}_{1.72} \mathrm{O}_{0.24} \mathrm{~N}_{0.15}$.

\section{Discussion}

Quantification of the effects of oxygen concentration on specific growth rate

Upon increasing the oxygen concentration from 20 to $75 \%$ air saturation the specific growth rate seems hardly affected by the oxygen concentration (Fig. 3). However, the specific growth rate decreases linearly with oxygen concentrations ranging from 75 to $250 \%$ air saturation. Similar effects of oxygen on the specific growth rate of microalgae were
Fig. 2 A typical growth curve of Nannochloropsis sp. during the batch run in a $1.5-\mathrm{L}$ flat-panel photobioreactor, followed by the turbidostat run at dissolved oxygen (DO) concentration ranging from 20 to $100 \%$ air saturation; $a$ batch, $b 100 \% \mathrm{DO}, c 75 \%$ $\mathrm{DO}, d 50 \% \mathrm{DO}$, e $25 \% \mathrm{DO}$, $f 20 \% \mathrm{DO}$

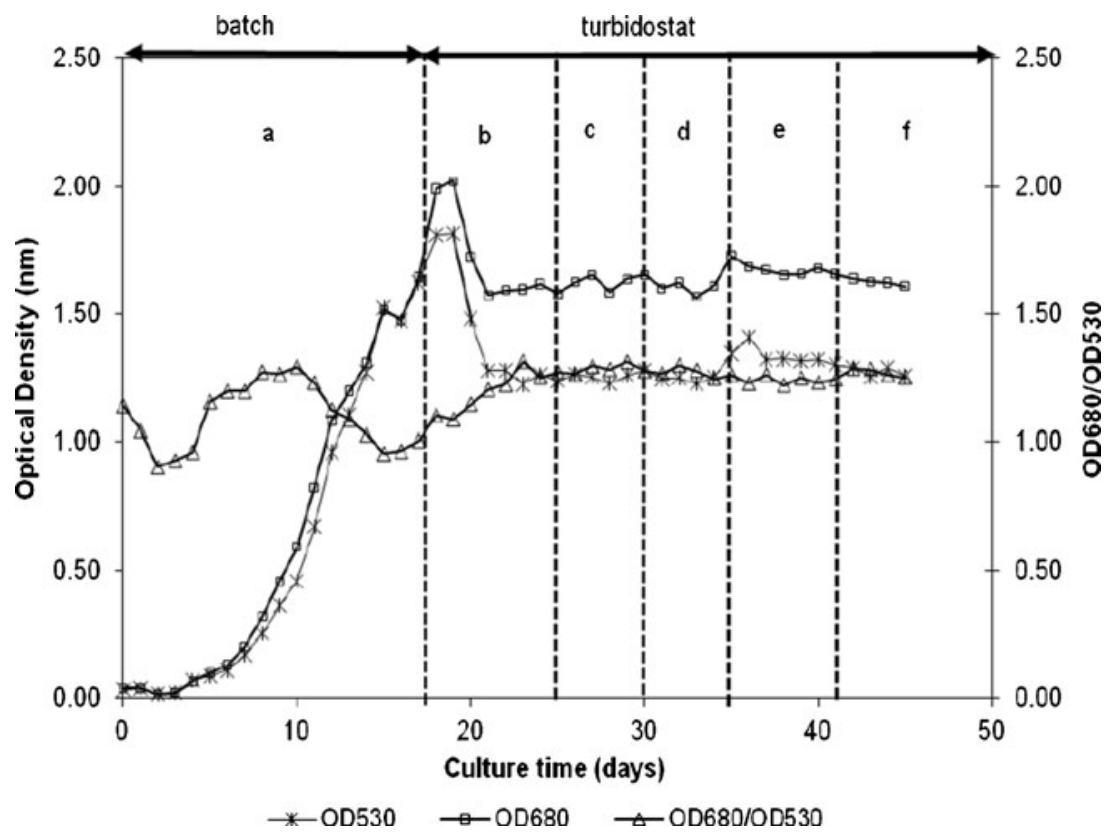




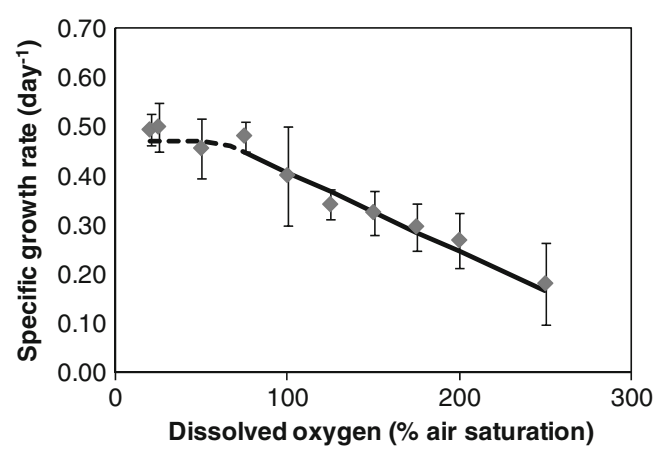

Fig. 3 Effects of oxygen concentration on the specific growth rate $\left(\right.$ day $^{-1}$ ) of Nannochloropsis sp. at an irradiance of $100 \mu \mathrm{mol}$ photons $\mathrm{m}^{-2} \mathrm{~s}^{-1}$

observed for Phaeodactylum tricornutum cultured at indoor conditions (Molina Grima et al. 2001), Spirulina platensis (Vonshak et al. 1996), Chlorella sorokiniana (Ugwu et al. 2007), Euglena gracilis (Kitaya et al. 2005), and for microalgae present in the sea ice community (McMinn et al. 2005). In most of these studies, the increase in oxygen concentration is claimed to be the major cause for inhibition the growth of the microalgae, but the effects of oxygen where mainly measured while changing the light, temperature, and other culture conditions at the same time. Among the varying medium conditions, especially the $\mathrm{pH}$ is one of the parameters that directly affects the specific growth rate. In our experiment, the $\mathrm{pH}$ is controlled via $\mathrm{CO}_{2}$ supply and this result in a constant concentration of $\mathrm{CO}_{2}$ in the medium at all oxygen concentrations applied. This was also the case in the recent study of Kliphuis et al. (2011), who studied the effects of oxygen on the growth of Chlamydomonas reinhardtii. They measured the growth rate at two different oxygen concentrations with oxygen as sole varying medium parameter and also found that the growth rate decreased with the increasing oxygen concentration (Kliphuis et al. 2011).

The specific growth rates of Nannochloropsis sp. measured at oxygen concentrations below $100 \%$ show a relatively high standard deviation, and it is not clear if the specific growth rate is indeed constant or decreasing with the oxygen concentration at these low applied $\mathrm{O}_{2}$ concentrations. One should realize that the in vivo growth data always reflect the balance of the physical and many cellular processes in which oxygen participates. Especially for low oxygen concentrations in the medium, it is very possible that the local concentration of oxygen at the Rubisco site is relatively high due to the photosynthesis activity of the cells. If the controlled oxygen concentration in the medium is lower than the oxygen concentration at the Rubisco site, the oxygen formed will diffuse from the cells into the medium and this will result in a constant specific growth rate at the lower oxygen concentrations. At higher oxygen concentrations in the medium, the oxygen will diffuse from the high concentration, through the cell membrane, to the
Rubisco site with the relative lower oxygen concentration. At the Rubisco site, the local $\mathrm{CO}_{2}$ and $\mathrm{O}_{2}$ concentrations will determine the balance between carboxylation (photosynthesis) and oxygenation (photorespiration).

Our results at oxygen concentrations above $75 \%$ air saturation prove that indeed an increase in oxygen concentration at constant $\mathrm{CO}_{2}$ concentration in the medium leads to a linearly decrease $\left(R^{2}=0.95\right)$ of the specific growth rate of Nannochloropsis sp. at low light intensity. An increase in oxygen concentration from $75 \%$ to $250 \%$ air saturation results in a decrease of the specific growth rate of the algae from $0.48 \pm 0.40$ day $^{-1}$ to $0.18 \pm 0.01$ day $^{-1}$.

Prediction of the ratio between carboxylation and oxygenation using in vitro data

In the dark reaction of the photosynthesis, the enzyme Rubisco shows carboxylase activity and is thus responsible for fixation of $\mathrm{CO}_{2}$. The carboxylase activity of Rubisco follows Michaelis-Menten kinetics taking into account the competitive inhibition by oxygen (Tchernov et al. 2008).

$v_{\mathrm{c}}=\frac{v_{\mathrm{c} \max } \times C_{\mathrm{CO} 2}}{C_{\mathrm{CO} 2}+K_{\mathrm{mc}}\left(1+\frac{C_{\mathrm{O} 2}}{K_{\mathrm{mo}}}\right)} \quad\left(\mu \mathrm{mol} \mathrm{CO}_{2} \mathrm{~min}^{-1} \mathrm{mg}^{-1}\right.$ protein $)$

where $v_{\mathrm{c}}$ and $v_{\mathrm{cmax}}$ represent the activity and maximum activity of the carboxylation reaction, respectively, while $K_{\mathrm{mc}}$ and $K_{\mathrm{mo}}$ represents the Michaelis-Menten constant of the Rubisco for $\mathrm{CO}_{2}$ and $\mathrm{O}_{2}$. In the presence of oxygen, the enzyme Rubisco shows oxygenase activity, which suffers from competitive inhibition by $\mathrm{CO}_{2}$. The oxygenase activity can be described by

$v_{\mathrm{o}}=\frac{v_{\mathrm{o} \text { max }} \times C_{\mathrm{O} 2}}{C_{\mathrm{O} 2}+K_{\mathrm{mo}}\left(1+\frac{C_{\mathrm{CO} 2}}{K_{\mathrm{mc}}}\right)} \quad\left(\mu \mathrm{mol} \mathrm{O} \mathrm{min}^{-1} \mathrm{mg}^{-1}\right.$ protein $)$

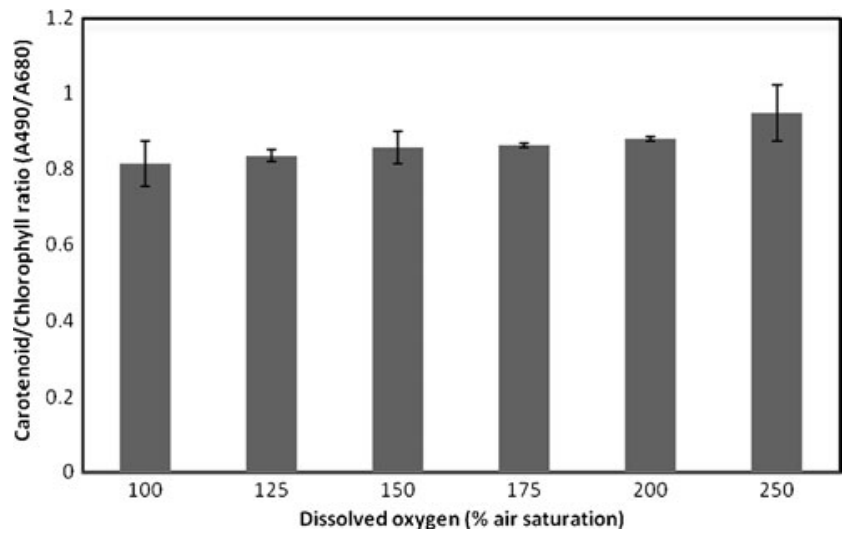

Fig. 4 Effects of oxygen concentration on the ratio between carotenoids and chlorophyll of Nannochloropsis sp. cultured at an irradiance of $100 \mu \mathrm{mol}$ photons $\mathrm{m}^{-2} \mathrm{~s}^{-1}$. The absorption at $490 \mathrm{~nm}$ $\left(\mathrm{A}_{490}\right)$ is used as measure for the carotenoid, and the absorption at $678 \mathrm{~nm}\left(\mathrm{~A}_{678}\right)$ is used as measure $(n=6)$ for the chlorophyll 
Table 2 Measured elemental composition of Nannochloropsis sp. grown at an irradiance of $100 \mu \mathrm{mol}$ photons $\mathrm{m}^{-2} \mathrm{~s}^{-1}$ at DO concentration of 100 and $300 \%$ air saturation, corrected for $3.63 \%$ ash and $3.38 \%$ moisture content

\begin{tabular}{lllll}
\hline $\begin{array}{l}\text { Oxygen concentration } \\
(\% \text { air saturation })\end{array}$ & \multicolumn{4}{l}{ Elemental composition $(\% w / w)$} \\
\cline { 2 - 5 } & $\mathrm{C}$ & $\mathrm{H}$ & $\mathrm{O}$ & $\mathrm{N}$ \\
\hline 100 & 60.97 & 9.05 & 19.42 & 10.56 \\
300 & 61.29 & 8.87 & 19.35 & 10.48 \\
\hline
\end{tabular}

where $v_{\mathrm{o}}$ and $v_{\mathrm{omax}}$ are the activity and maximum activity of the oxygenation reaction.

The rates of the carboxylation and oxygenation reaction can be combined, to deduce that the ratio between both reactions linearly decreases with the ratio of $\mathrm{CO}_{2}$ and $\mathrm{O}_{2}$ concentration in the vicinity of the Rubisco enzyme:

$\frac{v_{\mathrm{c}}}{v_{\mathrm{o}}}=\frac{v_{\mathrm{cmax}} \times K_{\mathrm{mo}}}{v_{\mathrm{omax}} \times K_{\mathrm{mc}}} \times \frac{C_{\mathrm{CO} 2}}{C_{\mathrm{O} 2}}$

Tchernov et al. (2008) obtained $K_{\mathrm{mc}}$ values of $7-10 \mu \mathrm{M}$ and a $v_{\text {cmax }}$ between 0.85 and $1 \mu \mathrm{mol} \mathrm{CO} \mathrm{CO}_{2} \mathrm{ming}^{-1}$ protein from in vitro experiments on isolated Rubisco and a $K_{\text {mo }}$ value of about $1 \mathrm{mM} \mathrm{O}_{2}$ and a $v_{\text {omax }}$ value of $3.9 \mu \mathrm{mol}$ $\mathrm{O}_{2} \min ^{-1} \mathrm{mg}^{-1}$. With these kinetic parameters determined for isolated Nannochloropsis sp. and the measured concen- trations of dissolved oxygen and carbon dioxide in the medium, we were able to predict the ratio between carboxylation and oxygenation reaction.

The carbon dioxide concentration in the medium is calculated using Henry's law with the Henry coefficient of 161.3 MPa for pure $\mathrm{CO}_{2}$ in water of $298 \mathrm{~K}$. The solubility of $\mathrm{CO}_{2}$ in the aqueous modified Zou medium (Table 1) corresponds with $0.37 \% \mathrm{CO}_{2}$ in the gas phase that is used to keep the $\mathrm{pH}$ in the medium at 7.8. The $\mathrm{pKa}$ value for $\mathrm{CO}_{2}$ in water at $298 \mathrm{~K}$ is corrected for the temperature and for the ions that were present in the modified Zou medium according to Stumm and Morgan (1995), resulting in $\mathrm{pKa}=$ 6.16, and this indicates that most of the $\mathrm{CO}_{2}$ is present in the form of $\mathrm{HCO}_{3}{ }^{-}$. The resulting $\mathrm{CO}_{2}$ concentration in the liquid is $97.7 \mu \mathrm{M}$. The oxygen concentration in the medium is also calculated using Henry's law with the Henry coefficient for $\mathrm{O}_{2}$ corrected for temperature and effects of solutes in the Zou medium (van't Riet and Tramper 1991). The concentration of $\mathrm{O}_{2}$ in the modified Zou medium at $100 \%$ air saturation is calculated to be $24.3 \mathrm{mM}$.

Prediction of the quantum yield from the ratio between carboxylation and oxygenation

The ratio between the carboxylation and oxygenation is used to predict the maximum possible QY at the different oxygen concentrations used in the experiments. Figure 5

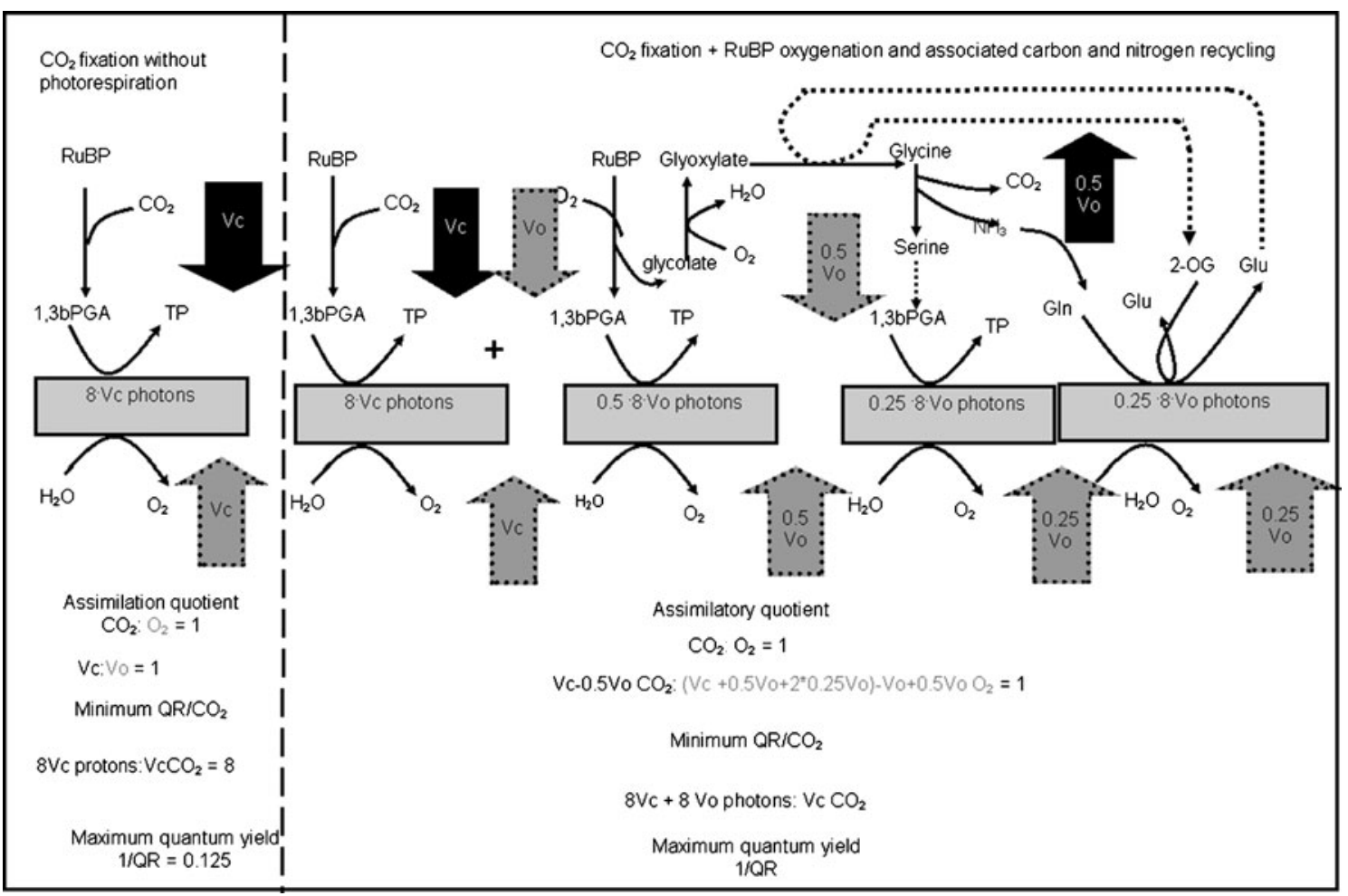

Fig. 5 Photorespiration pathway of microalgae. Left hand side photosynthesis without photorespiration. Right hand side photorespiration (adapted from Foyer et al. 2009) 


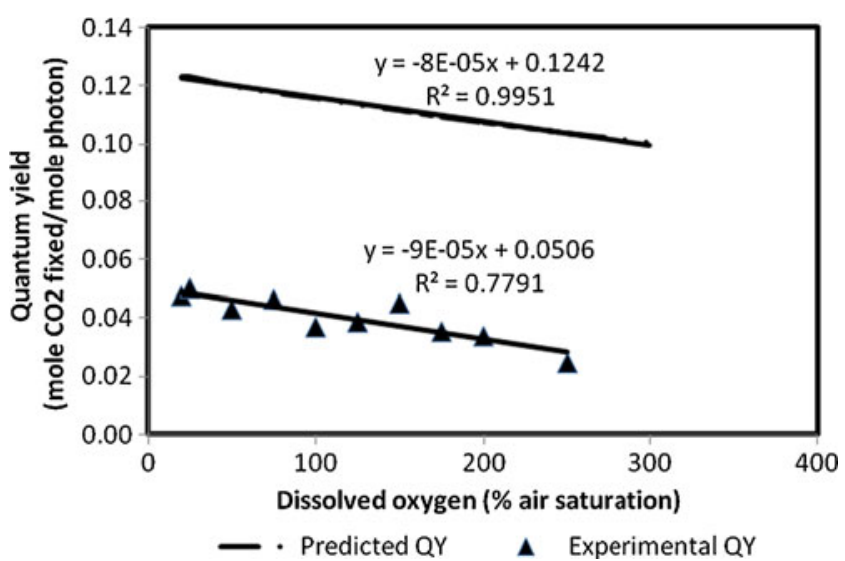

Fig. 6 The effect of oxygen concentration on the in vivo quantum yield of Nannochloropsis sp. measured at an irradiance of $100 \mu \mathrm{mol}$ photons $\mathrm{m}^{-2} \mathrm{~s}^{-1}$ and compared with predicted quantum yields based on in vitro data on the kinetics for carboxylation and oxygenation of Rubisco isolated from Nannochloropsis sp. (Tchernov et al. 2008)

provides an overview of the reactions involved in photorespiration. In this figure, the number of $\mathrm{CO}_{2}$ molecules converted in the carboxylation reaction catalyzed by the Rubisco enzyme is depicted by $v_{\mathrm{c}}$. Each mole of $\mathrm{CO}_{2}$ used to convert the ribulose biphosphate (RuBP) generates one mole of oxygen, and if $v_{\mathrm{c}} \mathrm{CO}_{2}$ molecules are fixed in this carboxylation reaction, $8 \times v_{\mathrm{c}}$ photons $\mathrm{s}^{-1}$ are needed. In the absence of oxygen (Fig. 5, left hand side), theoretically no photorespiration takes place and at maximum eight photons are required to fix one mole of carbon dioxide while one mole of oxygen is released (Foyer et al. 2009; Tredici 2010; Wingler et al. 2009). The number of $\mathrm{CO}_{2}$ molecules fixed (or oxygen evolved) per photon can be defined as the quantum yield. The theoretical maximum quantum yield is thus $0.125 \mathrm{~mol} \mathrm{CO}_{2}$ fixed (or oxygen evolved) $\mathrm{mol}^{-1}$ photons absorbed.

In the photorespiration pathway (Fig. 5, right hand side), the oxygenation reaction of oxygen competes with the carboxylation reaction of carbon dioxide with RuBP. The number of oxygen molecules used per second in the oxygenation reaction of the RuBP is depicted by $v_{\mathrm{o}}$. Upon reacting with oxygen, one mole of RuBP will be converted into one mole of 1,3bPGA and one mole of glycolate. The 1,3bPGA re-enters the Calvin cycle generating $0.5 v_{\mathrm{o}}$ moles of $\mathrm{O}_{2}$ at the expense of $0.5 v_{\mathrm{o}} \times 8$ mole photons s $\mathrm{s}^{-1}$, while the glycolate moves from the chloroplast into the peroxisome where it is converted into glyoxylate at the expense of $0.5 v_{\mathrm{o}}$ moles photons $\mathrm{s}^{-1}$. The glyoxylate is converted into serine, and during this reaction, $0.5 v_{\mathrm{o}}$ molecule of $\mathrm{CO}_{2}$ is generated and ammonium will be formed. In a series of reactions eventually $1,3 \mathrm{bPGA}$ is produced, which returns to the Calvin cycle and results in formation of $0.25 v_{0}$ of $\mathrm{O}_{2}$. Another $0.25 v_{\mathrm{o}}$ mole $\mathrm{s}^{-1}$ is generated as result of the formation of glutamate. Both reactions will cost $0.25 v_{\mathrm{o}} \times$ 8 photons $\mathrm{s}^{-1}$. The oxygenation reaction of $v_{\mathrm{o}}$ moles of RuBP s${ }^{-1}$ with $v_{\mathrm{o}}$ moles of $\mathrm{O}_{2}$ overall yields $0.5 v_{\mathrm{o}}$ moles of $\mathrm{CO}_{2}$ and $0.5 v_{\mathrm{o}}$ moles of $\mathrm{O}_{2} \mathrm{~s}^{-1}$ and requires $8 v_{\mathrm{o}}$ moles photon $\mathrm{s}^{-1}$ in total.

The minimum quantum requirement (RQ) of the combined oxygenation and carboxylation reaction during photorespiration is $8 v_{\mathrm{c}}+8 \quad v_{\mathrm{o}}$ moles photon $\mathrm{s}^{-1}$ per $v_{\mathrm{c}}$ moles of $\mathrm{CO}_{2} \mathrm{~s}^{-1}$ fixed. If the ratio between the carboxylation $v_{\mathrm{c}}$ and the oxygenation reaction $v_{\mathrm{o}}$ is known, the minimum quantum requirement can be predicted and thus the maximum quantum yield (1/RQ).

\section{Comparison of in vivo quantum yields with predicted yields using in vitro data}

In Fig. 6, the quantum yield calculated from the in vivo experiments is compared with the quantum yield that is predicted based on the in vitro experimental data. These results show that in both cases, the quantum yield decreases linearly with an increase in oxygen concentration in the medium. The calculated values for the in vivo quantum yields are lower than the predicted values for isolated Rubisco, as expected. The model predicts the maximal possible photo-
Table 3 Off-line measurements of oxygen effects on growth of Nannochloropsis sp. at different oxygen concentrations

\begin{tabular}{lccc}
\hline $\begin{array}{l}\text { Dissolved oxygen } \\
\text { \% air saturation) }\end{array}$ & $\begin{array}{l}\text { Cell concentration } \\
\left(\text { cells } \mathrm{mL}^{-1}\right) \times 10^{7}\end{array}$ & $\begin{array}{l}\text { Cell dry } \\
\text { weight }\left(\mathrm{g} \mathrm{L}^{-1}\right)\end{array}$ & $\begin{array}{c}\text { Total absorption } \\
\text { area }\left(\mathrm{m}^{2} \mathrm{~L}^{-1}\right)\end{array}$ \\
\hline 20 & $7.78 \pm 0.20$ & $0.46 \pm 0.01$ & \\
25 & $7.85 \pm 0.12$ & $0.48 \pm 0.02$ & \\
50 & $7.40 \pm 0.22$ & $0.45 \pm 0.00$ & \\
75 & $7.75 \pm 0.46$ & $0.46 \pm 0.01$ & $0.08 \pm 0.01$ \\
100 & $7.64 \pm 0.36$ & $0.44 \pm 0.01$ & $0.11 \pm 0.03$ \\
125 & $7.82 \pm 0.15$ & $0.54 \pm 0.12$ & $0.11 \pm 0.04$ \\
150 & $7.57 \pm 0.72$ & $0.66 \pm 0.13$ & $0.10 \pm 0.01$ \\
175 & $9.08 \pm 0.29$ & $0.57 \pm 0.05$ & $0.09 \pm 0.01$ \\
200 & $8.05 \pm 0.44$ & $0.60 \pm 0.02$ & \\
250 & $9.48 \pm 0.45$ & $0.65 \pm 0.05$ & \\
\hline
\end{tabular}


synthetic yield and assumes that all photons absorbed are directed to the photosynthesis and photorespiration reactions. In vivo part of the light is scattered by the cells and lost by diffusion, and the ATP and NADPH formed are not only used for growth but also for maintenance and therefore much lower quantum yields are found in reality. In addition, the model is based on data from in vitro experiments on the Rubisco, so it predicts the oxygenase and carboxylase activity of the Rubisco using the dissolved $\mathrm{O}_{2}$ and $\mathrm{CO}_{2}$ concentration in the medium. The surplus of ions in the hypertonic cellular medium affects the solubility of $\mathrm{CO}_{2}$ more than it affects the solubility of oxygen (Stumm and Morgan 1995; Van't Riet and Tramper 1991). The $\mathrm{CO}_{2} / \mathrm{O}_{2}$ ratio at the Rubisco in the living cells will thus be lower than in the medium, resulting in a lower ratio between the carboxylation/oxygenation and thus in lower in vivo quantum yields.

To compare the observed quantum yields QY (mole of $\mathrm{CO}_{2}$ fixed per mole of absorbed photons) with reported quantum yields of Nannochloropsis sp. (Chini Zittelli et al. 1999), they have also been expressed in gram biomass obtained per mol photons in the PAR range. For this, the value of QY is multiplied by the average value of the measured molecular weight of the biomass $\left(\mathrm{CH}_{1.75} \mathrm{O}_{0.24} \mathrm{~N}_{0.15}\right)$ of $19.7 \mathrm{gC}^{-\mathrm{mol}^{-1}}$ (Table 2) and the theoretical yield of biomass on carbon dioxide. The elemental balance over the growth reaction of the algae shows that maximally 1.08 mole of $\mathrm{CO}_{2}$ can be fixed per C-mole biomass if urea is used as $\mathrm{N}$-source for growth.

The values range from $0.92 \mathrm{~g} \mathrm{~mol}^{-1}$ at an oxygen concentration of $20 \%$ air saturation to $0.45 \mathrm{~g} \mathrm{~mol}^{-1}$ at $250 \%$ air saturation. These values are comparable with the values obtained for Nannochloropsis sp. in outdoor tubular photobioreactors with oxygen concentrations above $100 \%$ air saturation, which range from 0.46 to $0.74 \mathrm{~g} \mathrm{~mol}^{-1}$ (Chini Zittelli et al. 1999).

The decrease in quantum yields with increasing oxygen concentration is similar to the decrease that is predicted, based on the selectivity of the isolated Rubisco. The slope of both curves is virtually the same $\left(8 \times 10^{-5}\right.$ for the predicted values versus $9 \times 10^{-5}$ for the measured values). The similarity in slope strongly indicates that oxygen mainly affects the carboxylase and oxygenase activity of Rubisco at these sub-saturating light conditions.

This linear decrease in quantum yield is also observed for P. tricornutum (Molina Grima et al. 2001), for $S$. platensis (Vonshak et al. 1996), C. sorokiniana (Ugwu et al. 2007), and for E. gracilis (Kitaya et al. 2005) growing at controlled sub-saturating light conditions at oxygen concentrations starting at $100 \%$ air saturation. The decrease in quantum yield of S. platensis (Vonshak et al. 1996) and $C$. sorokiniana (Ugwu et al. 2007) proved to be accompanied by a gradual decrease in the ratio between variable and maximum fluorescence. This indicates that higher oxygen concentrations cause destruction of the chlorophyll via photo-oxidative inhibition. Similar effects are also observed in our experiments but only at an oxygen concentration of $250 \%$ air saturation. At this concentration the carotene/ chlorophyll ratio increases (Fig. 4) indicating that a surplus of carotenoids is formed or that the chlorophyll is damaged at higher oxygen concentrations. The higher cell density and cell dry weight observed (Table 3) indicate towards extra formation of carotenoids, to protect the cells against photo-oxidative damage of the chlorophyll.

\section{Conclusion}

The effects of oxygen on growth of Nannochloropsis sp. at low irradiance have been determined at controlled culture and light conditions. An increase of the oxygen concentration from 20 to $75 \%$ air saturation showed no obvious effect of oxygen concentration on specific growth rate. A linear decline in the specific growth rate and quantum yield was found when oxygen concentration increased from $75 \%$ to $250 \%$ air saturation. Our findings indicate that at the subsaturating light conditions used, the oxygen as such mainly affects the carboxylation/oxygenation ratio of the Rubisco and hardly influences the growth rate c.q. quantum yield via other photo-oxidative stress reactions.

To improve the productivity of Nannochloropsis sp. in large-scale closed tubular photobioreactors, the oxygen level needs to be controlled. As light and $\mathrm{O}_{2}$ simultaneously influence the photosynthesis, we need to further investigate synergetic effects of high irradiance and oxygen on growth for optimization of productivity in the closed photobioreactors.

Acknowledgment This work was financially supported by The Royal Thai Government, via the Office of Civil Service commission (OCSC), Thailand.

Open Access This article is distributed under the terms of the Creative Commons Attribution Noncommercial License which permits any noncommercial use, distribution, and reproduction in any medium, provided the original author(s) and source are credited.

\section{References}

Cheng-Wu Z, Zmora O, Kopel R, Richmond A (2001) An industrial-size flat plate glass reactor for mass production of Nannochloropsis sp. (Eustigmatophyceae). Aquaculture 195:35-49

Chini Zittelli G, Lavista F, Bastianini A, Rodolfi L, Vincenzini M, Tredici MR (1999) Production of eicosapentaenoic acid by Nannochloropsis sp. cultures in outdoor tubular photobioreactors. J Biotechnol 70:299-312

Chini Zitelli G, Rodolfi L, Tredici MR (2003) Mass cultivation of Nannochloropsis sp. in annualar reactors. J Appl Phycol 15:107-114

Duboc P, Marison I, von Stockar U (1999) Quantitative calorimetry and biochemical engineering. In: Kemp RB (ed) Handbook of 
thermal analysis and calorimetry. Elsevier Science, London, pp 267-365

Foyer CH, Bloom AJ, Queval G, Noctor G (2009) Photorespiratory metabolism: genes, mutants, energetics, and redox signaling. Annu Rev Plant Biol 60:455-484

Kitaya Y, Azuma H, Kiyota M (2005) Effects of temperature, $\mathrm{CO}_{2} / \mathrm{O}_{2}$ concentrations and light intensity on cellular multiplication of microalgae, Euglena gracilis. Adv Space Res 35: $1584-1588$

Kliphuis AMJ, Martens DE, Janssen M, Wijffels RH (2011) Effect of $\mathrm{O}_{2}: \mathrm{CO}_{2}$ Ratio on the primary metabolism of Chlamydomonas reinhardtii. Biotechnol Bioeng. doi:10.1002/bit.23194

Livansky K (1996) Effects of $\mathrm{O}_{2}, \mathrm{CO}_{2}$ and temperature on the light saturated growth of Scenedesmus obliquus. Algol Stud 82:69-82

McMinn A, Pankowski A, Delfatti T (2005) Effect of hyperoxia on the growth and photosynthesis of polar sea ice microalgae. J Phycol 41:732-741

Molina Grima E, Fernandez J, Acien FG, Chisti Y (2001) Tubular photobioreactor design for algal culture. J Biotechnol 92:113131

Ogawa T, Fujii T, Aiba S (1980) Effect of oxygen on the growth (yield) of Chlorella vulgaris. Arch Microbiol 127:25-31

Ohnishi N, Allakhverdiev SI, Takahashi S, Higashi S, Watanabe M, Nishiyama Y, Murata N (2005) Two-step mechanism of photodamage to photosystem II: step 1 occurs at the oxygen-evolving complex and step 2 occurs at the photochemical reaction center. Biochemistry 44:8494-8499

Pulz O (2001) Photobiorectors; production systems for phototrophic microorganisms. Appl Microbiol Biotechnol 57:287-293

Richmond A, Cheng-Wu Z (2001) Optimization of a flat plate glass reactor for mass production of Nannochloropsis sp. outdoors. J Biotechnol 85:259-269
Stumm W, Morgan JJ (1995) Aquatic chemistry chemical equilibria and rates in natural water, 3rd edn. Wiley, New York

Sukenik A (1991) Ecophysiological considerations in the optimization of Eicosapentaenoic acid production by Nannochloropsis sp. (Eustigmatophyceae). Bioresour Technol 35:263-269

Sukenik A, Tchernov D, Kaplan A, Huertas E, Lubian LM, Livne A (1997) Uptake, efflux and photosynthetic utilization of inorganic carbon by the marine Eustigmatophyte Nannochloropsis sp. J Phycol 33:969-974

Tchernov D, Livne A, Kaplan A, Sukenik A (2008) The kinetic properties of ribulose-1,5-bisphosphate carboxylase/oxygenase may explain the high apparent photosynthetic affinity of Nannochloropsis sp. to ambient inorganic carbon. Isr J Plant Sci 56:37-44

Tredici MR (2010) Photobiology of microalgae mass cultures: understanding the tools for the next green revolution. Adv Biochem Eng Biot 1:143-162

Ugwu C, Aoyagi H, Uchiyama H (2007) Influence of irradiance, dissolved oxygen concentration, and temperature on the growth of Chlorella sorokiniana. Photosynthetica 45:309-311

Van't Riet K, Tramper J (1991) Basic bioreactor design. Marcel Dekker, USA

Vonshak A, Torzillo G, Accolla P, Tomaselli L (1996) Light and oxygen stress in Spirulina platensis (cyanobacteria) grown outdoors in tubular reactors. Physiol Plant 97:175-179

Weissman JC, Goebel RP (1988) Photobioreactor design: mixing, carbon utilization, and oxygen accumulation. Biotech Bioeng 31:336-344

Wingler A, Lea PJ, Quick WP, Leegood RC (2009) Photorespiration: metabolic pathways and their role in stress protection. Phil Trans R Soc Lond 355:1517-1529

Zou N, Richmond A (1999) Effect of light-path length in outdoor flat plate reactors on output rate of cell mass and of EPA in Nannochloropsis sp. J Biotechnol 70:351-356 